\title{
Awareness Of Patient's Responsibilities Amongst the Patients Admitted in Various Hospitals in Belagavi City
}

Supriya J Kulkarni ${ }^{1}$, M.A. Udachankar ${ }^{2}$, Rinku Porwal ${ }^{3}$, S.C. Dharwad ${ }^{4}$, Jayatheerth Kulkarni ${ }^{5}$

${ }^{1}$ Associate Professor Department Materia Medica, KLE Homoeopathic Medical College and Hospital Belagavi.

${ }^{2}$ Principal and Head, Department Materia Medica, KLE Homoeopathic Medical College and Hospital Belagavi.

${ }^{3}$ Assistant Professor, Forensic Medicine \& Toxicology A.M Shaikh Homoeopathic Medical College Belagavi.

${ }^{4}$ Director Clinical Services KLE Centenary Charitable Hospital, Belagavi.

${ }^{5}$ Assistant Professor, Forensic Medicine \& Toxicology KLE Homoeopathic Medical College and Hospital Belagavi

Corresponding Author: Supriya Kulkarni

E-mail: kulkarnijsupriya30@gmail.com

\section{ABSTRACT}

Background: Successful medical care requires ongoing collaboration between patients and physicians. Their partnership requires both individuals to take an active role in the healing process. Autonomous, competent patients control the decisions that direct their health care. With that exercise of self-governance and choice, comes a number of responsibilities. These responsibilities are presented to patients in the spirit of mutual trust and respect. Hence the objective of this study is to assess the awareness of admitted patients in various hospitals in Belagavi about their responsibilities.

Methodology: A cross sectional observational study was conducted amongst the admitted patients of various hospitals in Belagavi, for a period of three months. Data were collected using pre-tested questionnaire forms. The collected data was analyzed with SPSS V.20software. Analyzed Results were expressed as percentage using appropriate tables and figures.

Results: 140 IPD patients accomplished the questionnaire on the awareness of patient's responsibilities of which $76.14 \%$ patients were aware and $23.86 \%$ were unaware of their responsibilities towards the health care.

Conclusions: This study concludes that a large number of IPD patients are aware of their responsibilities and also signifies the importance of educating the remaining small number of IPD patients about their responsibilities.

Key words: patient's responsibilities, awareness, responsibility, Belagavi

\section{Introduction}

The American Medical Association has provided a list of patient responsibilities, said to be derived from patient autonomy [1]. What are the basic responsibilities which patients should be aware of [2] :

- Providing accurate and complete information.

- Asking questions

- Following instructions given by doctors 
- Following facility, rules and regulations

- Showing Respect and thoughtfulness

- Meeting financial commitments

- To follow treatment plan.

Madhok from India has reported doctors being, thrashed and abused by lay public for a trivial fault. According to them the causes of violence were lack of communication between doctor and patient, poor image of medical profession, lack of faith in judicial system and police, besides insufficient security for doctors [3].

A report from Bangladesh also throws light on fact that violence in healthcare system has been increasing at alarming level [4]. A national survey in Australia revealed that 58\% of General Practitioners had experienced verbal abuse and $18 \%$ experienced property damage [5]. The medical profession and medical ethics currently place a greater emphasis on physician responsibility than patient responsibility. This imbalance is not due to accident or a mistake but, rather is motivated by strong moral reasons. As we debate the nature and extent of patient responsibility it is important to keep in mind the reasons for giving a relatively minimal role to patient responsibility in medical ethics [6].

\section{Factors Influencing Patient Participation in Health Care Decision-Making are affected by individual factors, such as}

- Demographic characteristics [7-8];

- Personal characteristics (reads a lot, is mentally ok, can express himself) [6,9];

- Level of acculturation [7],

- Cultural knowledge and beliefs [9],

- Values and practices concerning health and care [7],

- Having physical ability, cognitive and emotional relation with others [9-10],

- Knowledge, beliefs, values and experiences in regard to mainstream health care services [7]

This study is to find out whether inpatients are aware of their responsibilities or they have to be educated in ethical and effective counselling methods for understanding their role and duties which will contribute to increasing patients' involvement in their care and also factors affecting their awareness of in patient's responsibilities. The study was aimed to study the awareness of inpatients responsibilities towards hospital, doctors and their treatment

\section{METHODOLOGY}

Source Of Data: The patients admitted in IPD of various hospitals of Belagavi city, with willingness to participate in survey were taken. Informed written consent was taken from the patients after obtaining detailed history. Evaluation was done with the help of performed parameters.

Research Design: Case series observational study

Study Period: 3 Months

Sample Size: 140

Tool: Pretested validated questionnaire

Inclusion Criteria

- In patients who are conscious and can understand and speak

- Either sex

- Age from 18 and above

Exclusion Criteria

- Unconscious ICU patients 
- Patients less than 18 years

- Patients suffering from terminal illness

Method of collection of data

Patients were selected on the basis of inclusion \& exclusion criteria. Minimum sample

\section{RESULTS}

Table 1: Gender based awareness: Descriptive Statistics

\begin{tabular}{|c|c|c|c|c|}
\hline Gender & $\begin{array}{c}\text { Average } \\
\text { Awareness }\end{array}$ & $\begin{array}{c}\text { Std. Dev. of } \\
\text { Awareness }\end{array}$ & $\begin{array}{c}\text { Min } \\
\text { Awareness }\end{array}$ & $\begin{array}{c}\text { Max } \\
\text { Awareness }\end{array}$ \\
\hline F- 48 & 6.9 & 3.0 & 0 & 10 \\
\hline M-92 & 8.0 & 2.4 & 0 & 10 \\
\hline Grand Total- 140 & 7.6 & 2.7 & 0 & 10 \\
\hline
\end{tabular}

Graph 1: Occupation based awareness among male and female

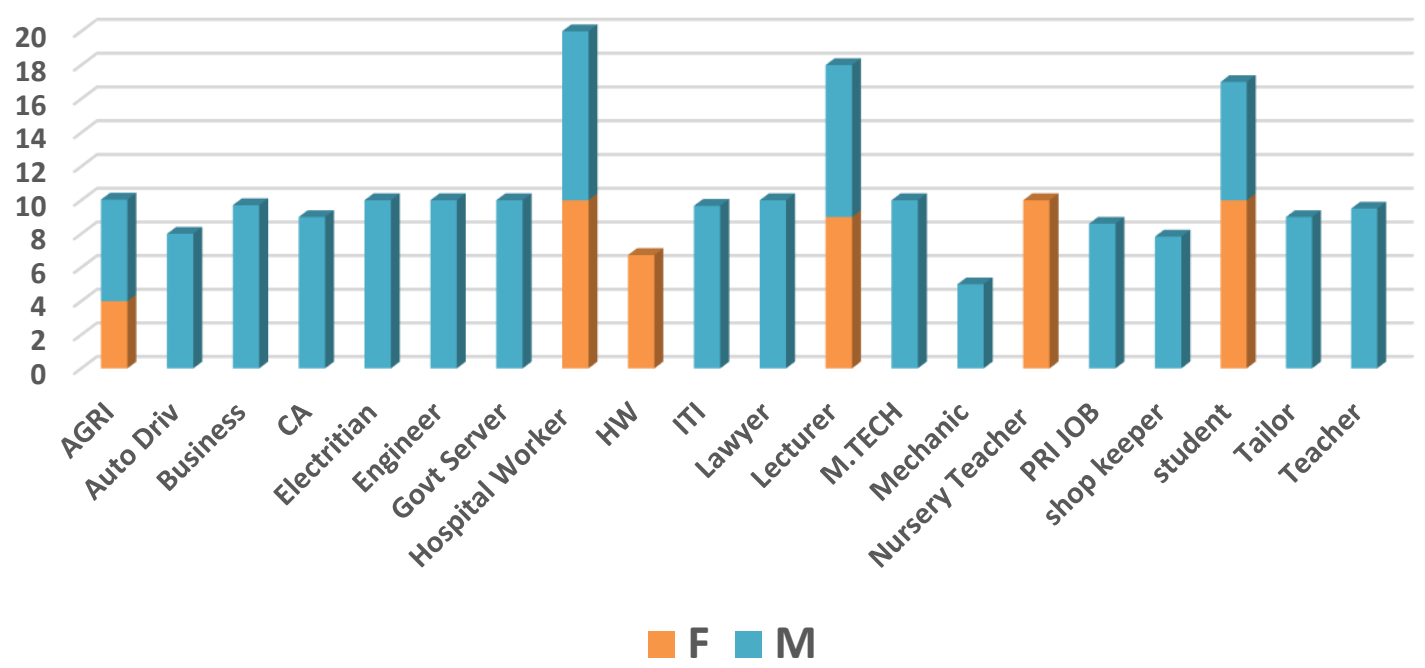

Table 2: Awareness among various age groups: Descriptive statistics

\begin{tabular}{|l|l|l|l|l|}
\hline Age group & $\begin{array}{l}\text { Average of } \\
\text { Aware }\end{array}$ & $\begin{array}{l}\text { Std Dev of } \\
\text { Aware }\end{array}$ & $\begin{array}{l}\text { Min of } \\
\text { Aware }\end{array}$ & Max of Aware \\
\hline $18-30$ & 7.5 & 2.859006 & 0 & 10 \\
\hline $30-50$ & 7.8 & 2.399863 & 1 & 10 \\
\hline $50-70$ & 7.5 & 2.856091 & 0 & 10 \\
\hline $70-90$ & 6.8 & 3.259175 & 0 & 10 \\
\hline Grand Total & $\mathbf{7 . 6}$ & $\mathbf{2 . 6 7 3 0 3 5}$ & $\mathbf{0}$ & $\mathbf{1 0}$ \\
\hline
\end{tabular}


Table 3: Awareness based on education and gender

\begin{tabular}{|l|l|l|l|l|l|}
\hline \multirow{2}{*}{ Education } & \multicolumn{5}{c|}{ Age group } \\
\cline { 2 - 7 } & \multicolumn{2}{|c|}{$\mathbf{1 8 - 3 0}$} & \multicolumn{2}{|c|}{$\mathbf{3 0 - 5 0}$} & \multicolumn{2}{c|}{$\mathbf{5 0 - 7 0}$} & \multicolumn{2}{c|}{$\mathbf{7 0 - 9 0}$} & $\begin{array}{c}\text { Grand } \\
\text { Total }\end{array}$ \\
\hline Graduate+ & 9 & 9 & 10 & 10 & 9 \\
\hline High school & 6 & 7 & 8 & 5 & 7 \\
\hline Higher secondary & 7 & 8 & 9 & 7 & 8 \\
\hline Primary & 8 & 6 & 7 & 10 & 7 \\
\hline Informal & 7 & 7 & 5 & 6 & 6 \\
\hline Illiterate & & 7 & 5 & & 6 \\
\hline Grand Total & 8 & 8 & 8 & 7 & 8 \\
\hline
\end{tabular}

Table 4: Chi-Squaretest for significance

Chi-square Test for significance

\begin{tabular}{|c|c|c|c|}
\hline Variables & $\begin{array}{c}\text { Pearson Chi- } \\
\text { Square }\end{array}$ & P-Value & $\begin{array}{c}\text { Q } \\
\text { Significant }\end{array}$ \\
\hline Occupation & 176.16 & 0.756 & Insignificant \\
\hline Age & 32.81 & 0.331 & Insignificant \\
\hline Education & 85.41 & 0.000 & Significant \\
\hline Gender & 20.77 & 0.023 & Significant \\
\hline
\end{tabular}

140 IPD patients accomplished the questionnaire on the awareness of patient's responsibilities of which. $76.14 \%$ patients were aware and $23.86 \%$ were unaware of their responsibilities towards health care. Factors influencing the awareness according to this study are as follows -

Education: Is significant association factor

Gender: Has significant association where males were more aware than females.

Age: Has no significant difference as awareness was equal among all the age group of IPD patients Occupation: Has no significant association with awareness.

\section{DISCUSSION}

Patient responsibilities are important towards health care and hospital and are required in health care ethics, but is not followed up to the mark by patients as they are more inclined towards rights than responsibilities. Our modern societies have always given special prominence to patients' rights, but rarely acknowledged the existence of their responsibilities. However, rights have to be fully balanced with obligations. Patients are not only duty-bound by the traditional relationship they have with medical professionals, but also by their role in society through healthcare. Nowadays, as societies cannot afford irresponsible behaviour from the public in health care systems, more attention has been paid to patients' duties. These do not just have moral consequences, but also legal ones. Can a patient be held responsible for a bad outcome in a medical treatment? Recent debates have shown that this question is a global problem, and it therefore 
requires an international overview. Such a study will help to clarify patients' duties and show how the legal system deals with them and what has been done so far to engage more patients in their own health. This survey helped me to understand the views of inpatients responsibilities towards hospitals and doctors. In our study we found out that $76.14 \%$ patients were aware and $23.86 \%$ were unaware of their responsibilities towards health care. No such studies were conducted on patient's responsibilities amongst the inpatients hence; this study reveals a valid data about the Awareness of inpatients responsibilities in various hospitals.

\section{What can be done?}

- In hospital-to identify less educated patients with help of questionnaire format and educate them.

- Globally this questionnaire can be filled online and applied globally.

- Mobile app can be developed on questionnaire and can be analysed.

- General rules and regulation can be displayed in the form of videos

What can be the outcome?

- Some services may be free in hospitals which can be brought to notice

- Medicines can be replaced and taken.

- Maximum benefits can be taken like ESI scheme and govt policy where even uneducated patients can be identified and informed.

- For all the above, good communication between admin department, PRO and Doctors with patients will help to take maximum benefits from the hospital.

The study was conducted only on inpatients of few hospitals in Belagavi city. An extensive study should be done including greater number of hospitals in more geographical regions. Further studies are needed to analyze the Awareness of patient's responsibility with the broader scope including various hospitals in different geographical locations.

\section{REFERENCES}

1. Gauthier CC. The virtue of moral responsibility and the obligations of patients. J Med Philos 2005;30(2):153-66.

2. https://www.arnothealth.org/patients-responsibilities

3. Madhok P. Violence against doctors. Bombay Hospital Journal 2009;51(2):301-2.

4. Ham Nazmul Ahasan, Aparna Das. Violence against doctors. J Medicine 2014;15:106-8.

5. Rasul CH. Violence towards doctors. Bangladesh Medical Journal. 2012;43(1):3-5.

6. Thompson AG. The meaning of patient involvement and participation in health care consultations: a taxonomy. Soc Sci Med 2007;64(6):1297-310.

7. Johnstone MJ, Kanitsaki O. Engaging patients as safety partners: some considerations for ensuring a culturally and linguistically appropriate approach. Health Policy 2009;90(1):1-7.

8. Davis RE, Jacklin R, Sevdalis N, Vincent CA. Patient involvement in patient safety: what factors influence patient participation and engagement? Health Expect 2007;10(3):259-67.

9. Bastiaens H, Van Royen P, Pavlic DR, Raposo V, Baker R. Older people's preferences for involvement in their own care: a qualitative study in primary health care in 11 European countries. Patient Educ Couns 2007;68(1):33-42.

10. Larsson IE, Sahlsten MJ, Sjostrom B, Lindencrona CS, Plos KA. Patient participation in nursing care from a patient perspective: a Grounded Theory study. Scand J Caring Sci 2007;21(3):313-20.

11. American Medical Association.1847."Code of Ethics, Chapter 1, Article II, Obligations of patients to their physicians. Reprented in J.Kartz."In the silent world of doctor and patient,231-233.New York: Free Press, 1984.

Acknowledgements: Dr.Animesh Jain Prof - HOD, Community Medicine, Kasturba Medical College, Mangalore, Dakashata Hospital, Belagavi, Navjeevan Hospital, Belagavi, Dr. Tyagi, Professor \& HOD, Dept. of Epidemiology \& Bio-statistics.

Conflict of interest: Nil

Financial grants for this paper: Nil 